\title{
Nipple-sparing mastectomy in breast cancer patients: The role of adjuvant radiotherapy (Review)
}

\author{
STEFAN JANSSEN $^{1,2}$, EDNA HOLZ-SAPRA ${ }^{3}$, DIRK RADES $^{2}$, ALEXANDER MOSER $^{4}$ and GABRIELA STUDER ${ }^{3}$ \\ ${ }^{1}$ Medical Practice for Radiotherapy and Radiation Oncology, Hannover; ${ }^{2}$ Department of Radiation Oncology, \\ University of Luebeck, Luebeck, Germany; ${ }^{3}$ Department of Radiation Oncology, University Hospital Zurich, \\ Zurich, Switzerland; ${ }^{4}$ Department of Gynecology and Obstetrics, Nordstadt Hospital, Hannover, Germany
}

Received June 3, 2014; Accepted February 19, 2015

DOI: $10.3892 / \mathrm{ol} .2015 .3084$

\begin{abstract}
The present study aimed to evaluate the role of adjuvant radiotherapy (RT) following nipple-sparing mastectomy (NSM) for patients with ductal carcinoma in situ and invasive breast cancer, based on the published literature. Currently, there is no standard for RT following NSM. NSM aims to spare the nipple areola complex (NAC) without compromising locoregional control. Long-term follow-up studies have begun to show promising results. A search of the English literature was performed using the Medline database and Cochrane central library, with the keywords 'nipple/areola-sparing mastectomy', 'whole skin mastectomy' and 'NAC preservation'. A total of 32 original studies with data on NSM in terms of locoregional control, NAC control, NAC necrosis and adjuvant RT were identified. The median locoregional and NAC recurrence rates were 3.2 and $1.4 \%$ (range, $0-28.4 \%$ and $0-3.7 \%$ ), respectively. The volume of remaining breast tissue following NSM was reported inconsistently. In 15 studies, RT was not mentioned. In the remaining 17 studies, RT was administered in 0-100\% of patients. Only 7 studies provided detailed information regarding the use of adjuvant RT. Adjuvant thoracic wall irradiation was not used in certain studies, not even for locoregionally advanced tumors. Overall, NSM appears a feasible treatment without increased risk of locoregional recurrence for selected patients. The role of adjuvant RT following NSM requires further clarification. The decision regarding adjuvant $\mathrm{RT}$ must be made in interdisciplinary tumor boards and with consideration of the individual situation of the patient.
\end{abstract}

Correspondence to: Dr Stefan Janssen, Medical Practice for Radiotherapy and Radiation Oncology, GSR Rundestrasse 10, Hannover D-30161, Germany

E-mail: st-janssen@gmx.net

Key words: nipple-sparing mastectomy, radiotherapy, breast cancer

\author{
Contents \\ 1. Introduction \\ 2. Database search \\ 3. Indications of NSM \\ 4. Oncological outcome and complications \\ 5. Adjuvant RT \\ 6. Comesis \\ 7. Disease control \\ 8. Complications \\ 9. NSM and adjuvant RT \\ 10. Conclusion
}

\section{Introduction}

Breast-conserving therapy (BCT) is the gold standard for the majority of patients with localized breast cancers. In $25 \%$ of breast cancer patients, a mastectomy is indicated for multi-centric or large tumors, and for local recurrence following BCT (1). Radical mastectomy is disfiguring, with removal of all the skin, the sub-mammarial fold and the nipple-areola complex (NAC). As a consequence, skin-sparing techniques have been introduced and demonstrated to provide similar outcomes compared with radical mastectomy (2). A study by Gerber et al (3) was the first to describe nipple-sparing mastectomy (NSM), which additionally saved the NAC, aiming to improve the esthetics and psychological results. The indications of NSM have been extended from a prophylactic scenario and small tumors distant from the NAC to larger and multi-centric tumors $(4,5)$. There are several studies and reviews on NSM (1,2,5-10), a number of which focus on oncological safety $(3,11-24)$, cosmetic outcome (24-29) and surgical techniques (24-32). The role of adjuvant radiotherapy (RT), including dose-fractionation concepts and techniques (6), remains unclear.

This review focuses on the use of adjuvant therapy following NSM to further clarify its role in the setting of this surgical technique.

\section{Database search}

A systematic review of the English literature was carried out using the Medline database and Cochrane Central Library. 
Keywords were 'nipple/areola-sparing mastectomy', 'whole skin mastectomy', 'NAC preservation' and 'adjuvant radiotherapy'. Each study presenting data on nipple-sparing mastectomy in ductal carcinoma in situ (DCIS) or breast cancer patients was reviewed focusing on the use of adjuvant RT. In addition, data on locoregional control, NAC control and NAC necrosis were collected. Studies reporting exclusively on prophylactic NSM and studies with $<10$ patients were excluded. The majority of study groups reported on NSM in a prophylactic setting and NSM for invasive cancer, however, the present review was limited to data from patients with DCIS and invasive breast cancer, as RT is not used in the prophylactic setting.

\section{Indications of NSM}

A total of 32 original studies concerning NSM in patients with DCIS and/or invasive cancer were identified. In 11 studies, the inclusion criterion for NSM was small tumors $>1-2 \mathrm{~cm}$ distant from the NAC $(1,33)$. In 21 studies, locally advanced and multi-centric tumors were included $(4,34,35)$. Only 5 studies excluded T3/4 tumors and patients with $\geq 4$ positive lymph nodes. Recent data has shown an increasing use of NSM in the more advanced disease stages $(4,34)$. It is generally agreed that involvement of the skin/NAC (1), inflammatory tumors (2) and Paget's disease (3) are contraindications for NSM. Undetected tumor involvement of the clinically non-involved NAC is a critical point. In a previous study, the rate of histopathological NAC involvement in patients treated with NSM ranged between 0 and $58 \%$ (6). Risk factors for involvement are tumor location, number of positive lymph nodes and lymphovascular invasion (36). Tumor size and distance from the NAC, as measured by magnetic resonance imaging, are correlated with an increased risk of NAC involvement (37). Almost all studies identified used intraoperative pathological assessment (frozen sections) of the subareolar tissue for deciding whether NSM could be carried out or not. In cases of involvement of the NAC, the complex was not spared $(25,29,33)$.

\section{Oncological outcome and complications}

The number of patients included in the identified studies ranged from 26 to 1,001 patients (median, 147 patients), and the follow-up period ranged from 10 to 156 months (median, 38.4 months). The data for these studies is summarized in Table I. In total, 8 studies provided follow-up data for 5 years or longer. The majority of the studies focused on oncological feasibility (locoregional control), safety and cosmetic outcomes. Locoregional recurrence in the treated breast occurred in $0-28.4 \%$ of cases (median, $3.2 \%$ of cases) and recurrence in the NAC in $0-3.7 \%$ of cases (median, $1.4 \%$ of cases). The rate of total NAC necrosis and partial NAC necrosis ranged from $0-10 \%$ and $0-28.2 \%$, with median values of 4.4 and $6.8 \%$, respectively. Only one study addressed the potential impact of post-operative radiation on NAC necrosis: Carlson et al observed no difference in nipple necrosis with $(\mathrm{n}=9)$ or without $(\mathrm{n}=36)$ the application of RT (32).

\section{Adjuvant RT}

In 15 studies, the administration of adjuvant RT was not mentioned. A total of 10 studies reported the percentage of

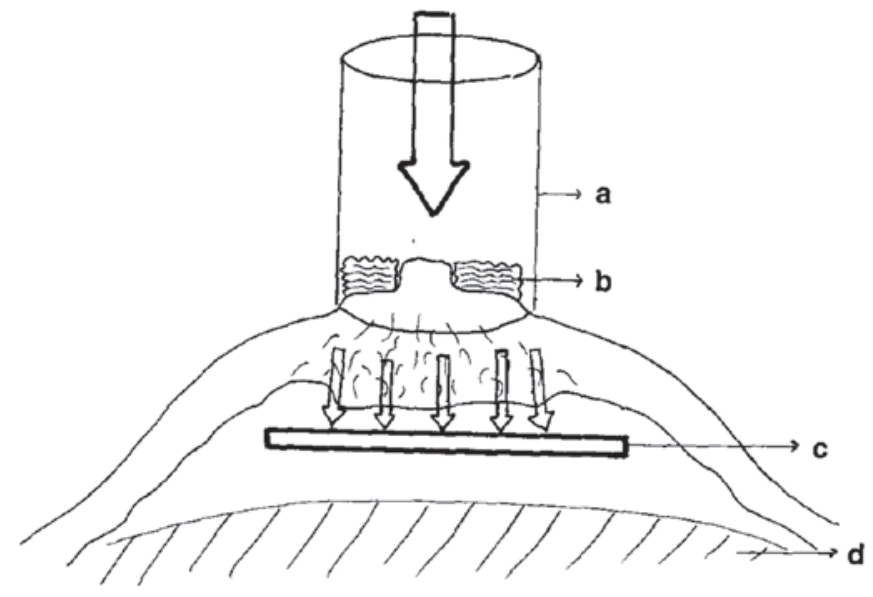

Figure 1. Electron intraoperative radiotherapy. a, sterile collimator of the linear accelerator; b, gauze over areola; c, protective lead; d, pectoralis major muscle. Figure reproduced from Petit et al (42) with permission.

patients treated with adjuvant RT without providing more details with respect to indication, technique and prescribed doses, while 7 studies described at least the indication for adjuvant RT. In total, RT was administered in 6 to $100 \%$ of patients according to 17 analyses.

Sakurai et al reported astudy of 788 patients without adjuvant RT following NSM in Union for International Cancer Control stage 0-IV patients (38). The locoregional recurrence rate of $8.2 \%$ and the NAC recurrence rate of $3.7 \%$ were comparable to the rates of other studies (Table 1) $(3,4,12-36,38-40,47,49)$.

Burdge et al (34) and Boneti et al (25) delivered 50 Gy to the thoracic wall (with or without lymphatic drainage) for tumors $>5 \mathrm{~cm}$ and/or in cases with $\geq 4$ positive lymph nodes. Moyer et al applied RT for resection margins $\leq 1 \mathrm{~mm}$ (28). In another study, the application of 50 Gy to the thoracic wall depended only on the treating physician's decision (proportion of irradiated patients not mentioned) (13).

Petit et al (42) performed RT exclusively to the NAC as either electron intraoperative RT (ELIOT; Fig. 1) (42) or as a single dose of $16 \mathrm{~Gy}$ (electron beams) a few days after surgery. The study reported a rate of locoregional recurrence of $1.4 \%$, with all recurrences distant from the NAC. The outcomes were not significantly different between the patients receiving ELIOT $(n=800)$ and those receiving delayed post-operative RT (n=201) (29). In six other studies providing statements on RT, a dose of 50 Gy was applied to the thoracic wall using conventional fractionation, with daily doses of 2 Gy administered on 5 days per week $(13,14,18,25,28,34)$. In the study by Rulli et al, the decision for adjuvant RT was based on the remaining breast tissue, with residual glandular tissue as an indication for RT $(\mathrm{n}=10)$ and no remaining tissue after NSM as an indication for withholding RT $(\mathrm{n}=50)(18)$. Only one study group found a significant difference in locoregional recurrence rate depending on the application of RT, as determined in 216 patients $(8.5 \%$ with RT vs. $28.4 \%$ without RT) (12). The tumor stage contributions in the two groups were not supplied. No observations of a higher rate of NAC necrosis following the application of adjuvant RT were reported.

No study was found commenting on the radiation boost volume, including the NAC area. 


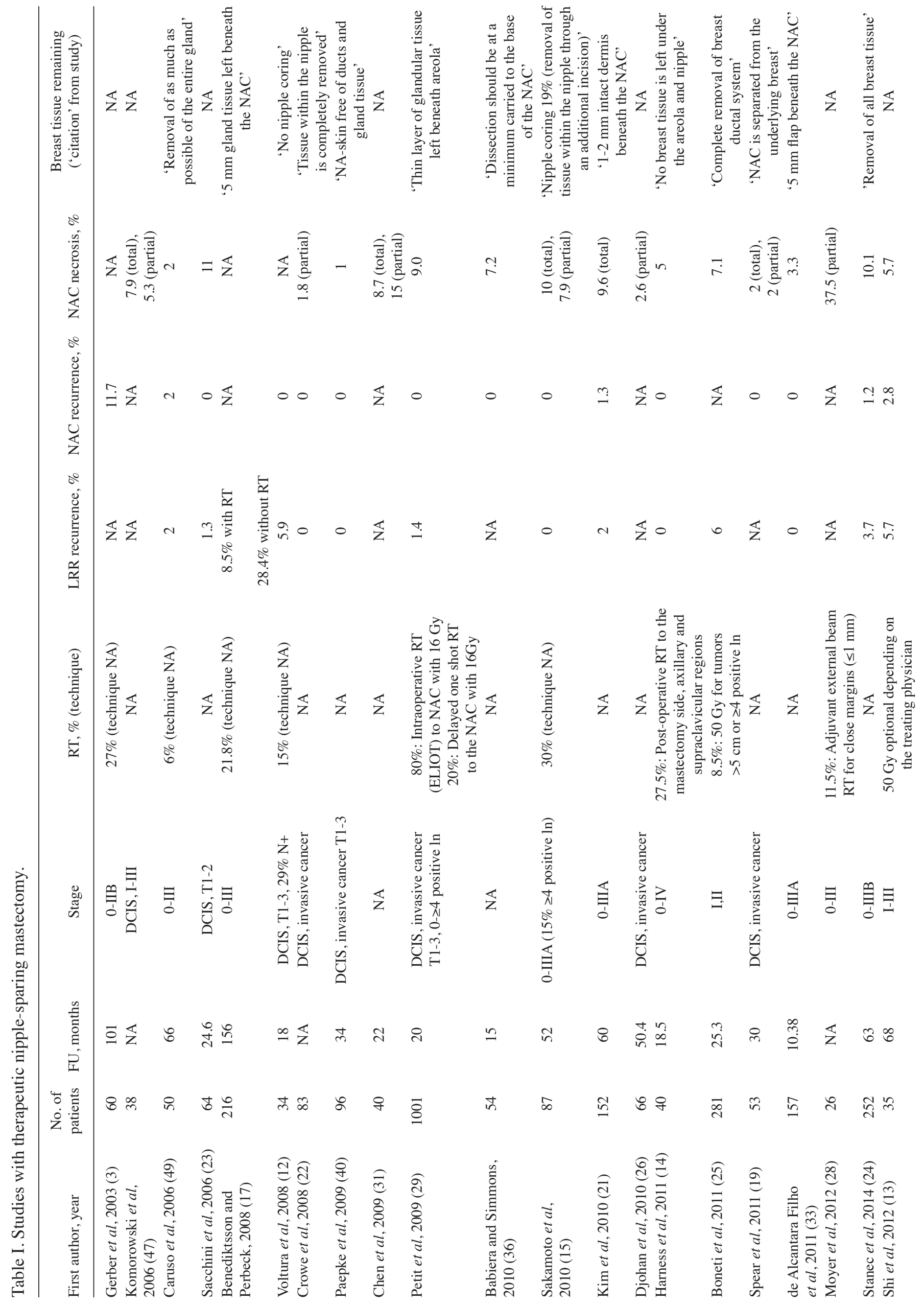




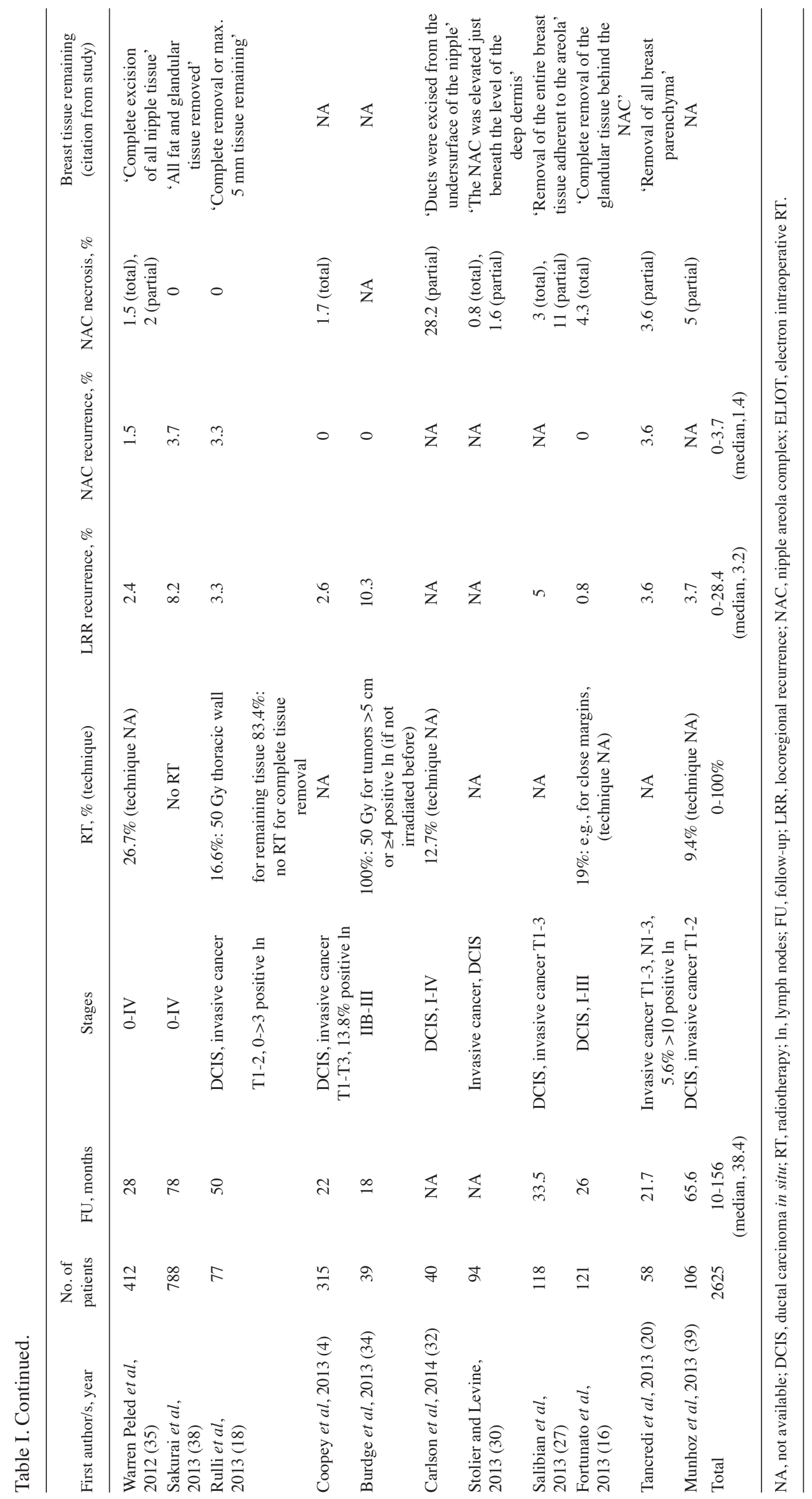




\section{Cosmesis}

Djohan et al (26) demonstrated high patient satisfaction rates with the appearance of the NAC following NSM, as determined by self-assessment and assessment by independent observers in a cohort of 141 patients, with a median follow-up period of 8 years. Other studies confirmed these good cosmetic outcomes $(25,27,28)$. Petit et al (29) achieved a global result of $8 / 10$, as rated by patients and surgeons, respectively, following ELIOT. Radiodystrophy, such as teleangiectasia, have been observed in $5.1 \%$ of 898 cases (39). None of the study groups reported an impaired cosmetic outcome following the addition of adjuvant RT.

\section{Disease control}

According to the reviewed literature, NSM appears a feasible option without an increased risk of locoregional recurrences for selected patients with invasive breast cancer and/or DCIS (12-16,19-24,39,40). Including a wide range of tumor $(\mathrm{T})$ and node $(\mathrm{N})$ stages, and tumor distances from the $\mathrm{NAC}$, the overall NAC recurrence rates were low, ranging from $0-3.7 \%$ (Table I).

\section{Complications}

As the majority of studies removed all breast tissue under the NAC, necrosis due to compromised blood supply is a significant complication to consider. Algaithy et al (41) and Gould et al (43) found a positive correlation between a higher rate of NAC necrosis and smoking history, type of incision, body mass index and hypertension/diabetes mellitus. The wide variation in percentage of NAC necrosis (0-28.2\%) could be explained by the lack of a standardized surgical technique (6).

None of the studies describing adjuvant RT revealed increased rates of partial or complete NAC necrosis following adjuvant RT. Only the study by Burdge et al (34), in which high-risk patients were treated with NSM and an adjuvant RT dose of $50 \mathrm{~Gy}$ to the thoracic wall, recorded complication rates following adjuvant RT. The study divided the complications into non-breast-related (6.7\%), such as radiation pneumonitis, and breast-related (30.8\%) complications. The study concluded NSM to be feasible in patients requiring adjuvant $\mathrm{RT}$, with complication rates similar to those following conventional mastectomy. In order to avoid increased complication rates a delayed reconstruction was suggested following completion of RT (34).

\section{NSM and adjuvant RT}

Of the 32 studies with primary data on NSM in DCIS and/or invasive breast cancer included in the present review, only 7 provided detailed information on adjuvant RT, while 15 studies did not mention the use of RT following NSM. Therefore, it remains unclear if RT was administered but not mentioned or more likely, not administered at all. The majority of studies used conventionally fractionated RT to the thoracic wall (and lymphatic drainage) in high-risk groups with tumors $>5 \mathrm{~cm}$ and/or with $\geq 4$ involved lymph nodes or close margins $(25,28,34)$. In the study by Rulli et al, RT was only performed in patients with remaining breast tissue after surgery (18). The largest contribution to the role of RT following NSM has been made by Petit et al (42). The study initially described an intraoperative approach with a 16-Gy dose (electron beams) to the NAC with a margin of $1 \mathrm{~cm}$ around the areola (ELIOT; Fig. 1), which is believed to be equivalent to a 40-45-Gy fractionated dose according to the linear-quadratic model (10). In 2009, the study group reported on a large patient cohort of 1,001 patients treated with either ELIOT $(n=800)$ or delayed RT $(16-$ Gy single dose a few days post-surgery; $n=201$ ) (29). The treatment outcomes in terms of locoregional control were similar. To the best of our knowledge, the only study showing a significant difference in locoregional control based on the application of RT following NSM was the study by Benediktsson and Perbeck (17). This may be explained by the fact that in every patient a plate of gland tissue (thickness, $5 \mathrm{~mm}$ ) with a $2 \mathrm{~cm}$ diameter was left around the NAC. According to national guidelines for BCT this would have been an indication for RT in any case (44-46). No comments were found on boost application/boost doses applied to the NAC.

In addition, there are two critical points to consider: 21 of the identified studies included high-risk patients with $\geq$ T3 tumors and/or lymph node involvement of $\geq 4$ positive lymph nodes, and did not comment on adjuvant RT $(5,20,21,27,33,38,40,47)$. For advanced TN stages, several recent national guidelines have recommended external beam RT to the whole thoracic wall, with or without irradiation of the lymphatic drainage system (44-46). A recent review of the Early Breast Cancer Trialists' Collaborative Group found that after mastectomy and axillary dissection, RT reduced recurrence and breast cancer mortality in women with 1-3 positive lymph nodes, even when systemic therapy was applied (48).

Petit et al (29) performed intraoperative RT (IORT) using a 16-Gy single dose exclusively to the NAC, which is not in accordance with the aforementioned most recent guidelines for more advanced tumors. In the study, $21 \%$ of the patients presented with either a T3 tumor or $\geq 4$ positive lymph nodes. In 2011, Petit et al (10) stated that conventional post-operative RT is usually delivered when patients present with high-risk factors. In the Japanese study that completely omitted RT in all patients, $12.5 \%$ of the patients presented with a stage T3 or T4 tumor (38).

The second critical point regarding the indication for RT in breast cancer patients following NSM is the amount of remaining tissue. In certain studies, a thin layer of tissue underneath the NAC was preserved, whereas in other studies, the NAC was completely removed. In the majority of patients, the entire breast tissue below the NAC was removed (Table I). Additionally, certain studies did not provide a detailed description of the surgical techniques used $(3,4,9,3,26,28,47)$. In other studies, the aim was to remove as much breast tissue as possible (49), or to leave a certain degree of breast tissue beneath the NAC in order to ensure the blood supply of the NAC $(17,18,29,33)$. In the latter situation, one would argue that adjuvant RT is necessary, as the remaining breast tissue is at risk for local recurrence. In cases of a T1/2N0 tumor, this could be performed with the ELIOT method, in agreement with the recommendations for 
an alternative use of IORT or accelerated partial breast irradiation following breast-conserving therapy $(50,51)$. In cases of a more advanced tumors or when IORT is unavailable, fractioned RT to the entire chest wall or post-operative single dose RT would be required. Petit et al (10) recommended $\mathrm{RT}$ to the NAC to reduce the risk of a local recurrence when breast tissue has been left behind the NAC, and if the distance between the tumor and the nipple is small. The role of a boost to the NAC is also debatable in patients with remaining breast tissue. None of the reviewed studies carried out a boost following thoracic wall RT. Omitting of RT after NSM may be discussed for low-stage tumors in patients with no remaining breast tissue behind the NAC.

\section{Conclusion}

Several retrospective studies have shown that NSM is a feasible option without an increased risk of local recurrences in selected patients with invasive breast cancer and/or DCIS. The surgical techniques and volume of resected breast tissue vary considerably.

Currently, there is no consensus regarding the use of adjuvant RT following NSM. For patients who meet the criteria for adjuvant RT following radical mastectomy (T3/T4, positive margins and lymph node involvement) adjuvant RT to the thoracic wall should be administered. In patients with a lower stage tumor, RT to only the NAC may be discussed. The decision for or against adjuvant RT following NSM requires an interdisciplinary tumor board, taking the benefits and potential risks for the individual patient into account.

\section{References}

1. Mallon P, Feron JG, Couturaud B, Fitoussi A, Lemasurier P, Guihard T, Cothier-Savay I and Reyal F: The role of nipple-sparing mastectomy in breast cancer: A comprehensive review of the literature. Plast Reconstr Surg 131: 969-984, 2013.

2. Tokin C, Weiss A, Wang-Rodriguez $\mathrm{J}$ and Blair SL: Oncologic safety of skin-sparing and nipple-sparing mastectomy: a discussion and review of the literature. Int J Surg Oncol 2012: 921821, 2012.

3. Gerber B, Krause A, Reimer T, Müller H, Küchenmeister I, Makovitzky J, Kundt G and Friese K: Skin-sparing mastectomy with conservation of the nipple-areola complex and autologous reconstruction is an oncologically safe procedure. Ann Surg 238: 120-127, 2003.

4. Coopey SB, Tang R, Lei L, Freer PE, Kansal K, Colwell AS, Gadd MA, Specht MC, Austen WG Jr and Smith BL: Increasing eligibility for nipple-sparing mastectomy. Ann Surg Oncol 20: 3218-3222, 2013.

5. Niemeyera M, Ettla J, Plattnera B, Schmida R, Müllerb D, Machensb HG, Kiechlea M and Paepkea S: Nipple-Sparing Mastectomy - Extended Indications and Limitations. Breast Care (Basel) 5: 253-258, 2010 .

6. Murthy V and Chamberlain RS: Defining a place for nipple sparing mastectomy in modern breast care: An evidence based review. Breast J 19: 571-581, 2013.

7. Chung AP and Sacchini V: Nipple-sparing mastectomy: Where are we now? Surg Oncol 17: 261-266, 2008.

8. Rusby JE, Smith BL and Gui GP: Nipple-sparing mastectomy. Br J Surg 97: 305-316, 2010.

9. Salani B, Riera R, Barrett J, Atallah AN and Bevilacqua JLB: Nipple- and areola-sparing mastectomy for the treatment of breast cancer. Cochrane Database of Systematic Reviews: doi: 10.1002/14651858.CD008932.pub2.

10. Petit JY, Veronesi U, Lohsiriwat V, Rey P, Curigliano G, Martella S, Garusi C, et al: Nipple-sparing mastectomy - is it worth the risk? Nat Rev Clin Oncol 8: 742-747, 2011.
11. Niemeyer M, Paepke S, Schmid R, Plattner B, Müller D, Kiechle M, Garusi C, et al: Extended indications for nipple-sparing mastectomy. Breast J 17: 296-299, 2011.

12. Voltura AM, Tsangaris TN, Rosson GD, Jacobs LK, Flores JI, Singh NK, Argani P and Balch CM: Nipple-sparing mastectomy: Critical assessment of 51 procedures and implications for selection criteria. Ann Surg Oncol 15: 3396-3401, 2008.

13. Shi A, Wu D, Li X, Zhang S, Li S, Xu H, Xie H and Fan Z: Subcutaneous Nipple-Sparing Mastectomy and Immediate Breast Reconstruction. Breast Care (Basel) 7: 131-136, 2012.

14. Harness JK, Vetter TS and Salibian AH: Areola and nipple-areola-sparing mastectomy for breast cancer treatment and risk reduction: Report of an initial experience in a community hospital setting. Ann Surg Oncol 18: 917-922, 2011.

15. Sakamoto N, Fukuma E, Higa K, Ozaki S, Sakamoto M, Abe S, Kurihara T and Tozaki M: Early results of an endoscopic nipple-sparing mastectomy for breast cancer. Indian J Surg Oncol 1: 232-239, 2010

16. Fortunato L, Loreti A, Andrich R, Costarelli L, Amini M, Farina M, Santini E and Vitelli CE: When mastectomy is needed: Is the nipple-sparing procedure a new standard with very few contraindications? J Surg Oncol 108: 207-212, 2013.

17. Benediktsson KP and Perbeck L: Survival in breast cancer after nipple-sparing subcutaneous mastectomy and immediate reconstruction with implants: A prospective trial with 13 years median follow-up in 216 patients. Eur J Surg Oncol 34: 143-148, 2008.

18. Rulli A, Caracappa D, Barberini F, Boselli C, Cirocchi R, Castellani E, Noya G and Covarelli P: Oncologic reliability of nipple-sparing mastectomy for selected patients with breast cancer. In Vivo 27: 387-394, 2013

19. Spear SL, Willey SC, Feldman ED, Cocilovo C, Sidawy M, Al-Attar A, Hannan C, Seiboth L and Nahabedian MY: Nipple-sparing mastectomy for prophylactic and therapeutic indications. Plast Reconstr Surg 128: 1005-1014, 2011.

20. Tancredi A, Ciuffreda L, Petito L, Natale F and Murgo R: Nipple-areola-complex sparing mastectomy: Five years of experience in a single centre. Updates Surg 65: 289-294, 2013.

21. Kim HJ, Park EH, Lim WS, Seo JY, Koh BS, Lee TJ, Eom JS, Lee SW, Son BH, Lee JW, et al: Nipple areola skin-sparing mastectomy with immediate transverse rectus abdominis musculocutaneous flap reconstruction is an oncologically safe procedure: A single center study. Ann Surg 251: 493-498, 2010.

22. Crowe JP, Patrick RJ, Yetman RJ and Djohan R: Nipple-sparing mastectomy update: One hundred forty-nine procedures and clinical outcomes. Arch Surg 143: 1106-1110, discussion 1110, 2008.

23. Sacchini V, Pinotti JA, Barros AC, Luini A, Pluchinotta A, Pinotti M, Boratto MG, Ricci MD, Ruiz CA, Nisida AC, et al: Nipple-sparing mastectomy for breast cancer and risk reduction: oncologic or technical problem? J Am Coll Surg 203: 704-714, 2006

24. Stanec Z, Žic R, Budi S, Stanec S, Milanović R, Vlajčić Z, Roje Z, Rudman F, Martić K, Held R and Božo G: Skin and nipple-areola complex sparing mastectomy in breast cancer patients: 15-year experience. Ann Plast Surg 73: 485-491, 2014.

25. Boneti C, Yuen J, Santiago C, Diaz Z, Robertson Y, Korourian S, Westbrook KC, Henry-Tillman RS and Klimberg VS: Oncologic safety of nipple skin-sparing or total skin-sparing mastectomies with immediate reconstruction. J Am Coll Surg 212: 686-693, discussion 693-695, 2011.

26. Djohan R, Gage E, Gatherwright J, Pavri S, Firouz J, Bernard S and Yetman R: Patient satisfaction following nipple-sparing mastectomy and immediate breast reconstruction: An 8-year outcome study. Plast Reconstr Surg 125: 818-829, 2010.

27. Salibian AH, Harness JK and Mowlds DS: Inframammary approach to nipple-areola-sparing mastectomy. Plast Reconstr Surg 132: 700e-708e, 2013.

28. Moyer HR, Ghazi B, Daniel JR, Gasgarth R and Carlson GW: Nipple-sparing mastectomy: Technical aspects and aesthetic outcomes. Ann Plast Surg 68: 446-450, 2012.

29. Petit JY, Veronesi U, Orecchia R, Rey P, Martella S, Didier F, Viale G, Veronesi P, Luini A, Galimberti V, et al: Nipple sparing mastectomy with nipple areola intraoperative radiotherapy: One thousand and one cases of a five years experience at the European institute of oncology of Milan (EIO). Breast Cancer Res Treat 117: 333-338, 2009.

30. Stolier AJ and Levine EA: Reducing the risk of nipple necrosis: Technical observations in 340 nipple-sparing mastectomies. Breast J 19: 173-179, 2013. 
31. Chen CM, Disa JJ, Sacchini V, Pusic AL, Mehrara BJ, GarciaEtienne CA, Cordeiro PG. Nipple-sparing mastectomy and immediate tissue expander/implant breast reconstruction. Plast Reconstr Surg 124: 1772-80, 2009.

32. Carlson GW, Chu CK, Moyer HR, Duggal C and Losken A: Predictors of nipple ischemia after nipple sparing mastectomy. Breast J 20: 69-73, 2014

33. de Alcantara Filho P, Capko D, Barry JM, Morrow M, Pusic A and Sacchini VS: Nipple-sparing mastectomy for breast cancer and risk-reducing surgery: The Memorial Sloan-Kettering Cancer Center experience. Ann Surg Oncol 18: 3117-3122, 2011.

34. Burdge EC, Yuen J, Hardee M, Gadgil PV, Das C, Henry-Tillman R, Ochoa D, Korourian S and Suzanne Klimberg V: Nipple skin-sparing mastectomy is feasible for advanced disease. Ann Surg Oncol 20: 3294-3302, 2013.

35. Warren Peled A, Foster RD, Stover AC, Itakura K, Ewing CA, Alvarado M, Hwang ES and Esserman LJ: Outcomes after total skin-sparing mastectomy and immediate reconstruction in 657 breasts. Ann Surg Oncol 19: 3402-3409, 2012.

36. Babiera G and Simmons R: Nipple-areolar complex-sparing mastectomy: Feasibility, patient selection, and technique. Ann Surg Oncol 17 (Suppl 3): 245-248, 2010.

37. Steen ST, Chung AP, Han SH, Vinstein AL, Yoon JL and Giuliano AE: Predicting nipple-areolar involvement using preoperative breast MRI and primary tumor characteristics. Ann Surg Oncol 20: 633-639, 2013.

38. Sakurai T, Zhang N, Suzuma T, Umemura T, Yoshimura G, Sakurai $\mathrm{T}$ and Yang Q: Long-term follow-up of nipple-sparing mastectomy without radiotherapy: A single center study at a Japanese institution. Med Oncol 30: 481, 2013.

39. Munhoz AM, Aldrighi CM, Montag E, Arruda EG, Aldrighi JM, Gemperli R, Filassi JR and Ferreira MC: Clinical outcomes following nipple-areola-sparing mastectomy with immediate implant-based breast reconstruction: A 12-year experience with an analysis of patient and breast-related factors for complications. Breast Cancer Res Treat 140: 545-555, 2013.

40. Paepke S, Schmid R, Fleckner S, Paepke D, Niemeyer M, Schmalfeldt B, Jacobs VR and Kiechle M: Subcutaneous mastectomy with conservation of the nipple-areola skin: Broadening the indications. Ann Surg 250: 288-292, 2009.

41. Algaithy ZK, Petit JY, Lohsiriwat V, Maisonneuve P, Rey PC Baros N, Lai H, Mulas P, Barbalho DM, Veronesi P and Rietjens M: Nipple sparing mastectomy: can we predict the factors predisposing to necrosis? Eur J Surg Oncol 38: 125-129, 2012.
42. Petit JY, Veronesi U, Orecchia R, Rey P, Didier F, Giraldo A, Luini A, De Lorenzi F, Rietjens M, Garusi C, et al: The nipple-sparing mastectomy: Early results of a feasibility study of a new application of perioperative radiotherapy (ELIOT) in the treatment of breast cancer when mastectomy is indicated. Tumori 89: 288-291, 2003.

43. Gould DJ, Hunt KK, Liu J, Kuerer HM, Crosby MA, Babiera $\mathrm{G}$ and Kronowitz SJ: Impact of surgical techniques, biomaterials, and patient variables on rate of nipple necrosis after nipple-sparing mastectomy. Plast Reconstr Surg 132: $330 \mathrm{e}-338 \mathrm{e}, 2013$.

44. National Comprehensive Cancer Network (NCCN) Practical Guidlines in Oncology-Breast Cancer- Version 1.2014.

45. Interdisciplinary S3 Guidelines for the Diagnosis, Treatment and Follow-up Care of Breast Cancer. Version 3, 2012. http://www. awmf.org/uploads/tx_szleitlinien/032-045OL_k_S3 Brustkrebs Mammakarzinom_Diagnostik_Therapie_Nachsorge_2012-07.pdf. (In German)

46. Senkus E, Kyriakides S, Penault-Llorca F, Poortmans P, Thompson A, Zackrisson S and Cardoso F: Primary breast cancer: ESMO Clinical Practice Guidelines for diagnosis, treatment and follow-up. Ann Oncol 24 Suppl 6: vi7-vi23, 2013.

47. Komorowski AL, Zanini V, Regolo L, Carolei A, Wysocki WM and Costa A: Necrotic complications after nipple- and areola-sparing mastectomy. World J Surg 30: 1410-1413, 2006.

48. EBCTCG (Early Breast Cancer Trialists' Collaborative Group), McGale P, Taylor C, Correa C, et al: Effect of radiotherapy after mastectomy and axillary surgery on 10-year recurrence and 20-year breast cancer mortality: meta-analysis of individual patient data for 8135 women in 22 randomised trials. Lancet 383: 2127-2135, 2014.

49. Caruso F, Ferrara M, Castiglione G, Trombetta G, De Meo L, Catanuto G and Carillio G: Nipple sparing subcutaneous mastectomy: Sixty-six months follow-up. Eur J Surg Oncol 32: 937-940, 2006

50. Smith BD, Arthur DW, Buchholz TA, Haffty BG, Hahn CA, Hardenbergh PH, Julian TB, Marks LB, Todor DA, Vicini FA, et al: Accelerated partial breast irradiation consensus statement from the American Society for Radiation Oncology (ASTRO). Int J Radiat Oncol Biol Phys 74: 987-1001, 2009.

51. Polgár C, Fodor J, Major T, Németh G, Lövey K, Orosz Z, Sulyok Z, Takácsi-Nagy Z and Kásler M: Breast-conserving treatment with partial or whole breast irradiation for low-risk invasive breast carcinoma - 5-year results of a randomized trial. Int J Radiat Oncol Biol Phys 69: 694-702, 2007. 